\title{
A comparison of radionuclide dispersion model performances for the Baltic Sea and Fukushima releases in the Pacific Ocean
}

\author{
R. Periáñez ${ }^{1}$, R. Bezhenar ${ }^{2}$, I. Brovchenko ${ }^{3}$, C. Cuffa ${ }^{4}$, M. Iosjpe ${ }^{5}$, K.T. Jung ${ }^{6}$, T. Kobayashi ${ }^{7}$, \\ and G. de With ${ }^{14}$ \\ ${ }^{1}$ Dpt Física Aplicada I, ETSIA, Universidad de Sevilla, Ctra Utrera km 1, 41013 Sevilla, Spain. \\ ${ }^{2}$ Ukrainian Center of Environmental and Water Projects, Glushkov av., 42, Kiev 03187, Ukraine. \\ 3 Institute of Mathematical Machine and System Problems, Glushkov av., 42, Kiev 03187, Ukraine. \\ 4 IRSN, BP 330, 83507 La Seyne sur Mer, France. \\ 5 NRPA, Grini naeringspark 13, NO-1332 Osteras, Norway. \\ ${ }^{6}$ KIOST, 787 Hean-ro, Sangnok-gu, Ansan-si, Gyeonggi-do 426-744, Republic of Korea. \\ 7 JAEA, 2-4 Shirakata Shirane, Tokai, Ibaraki 319-1195, Japan. \\ 8 IEN, Rua Hélio de Almeida 75, Ilha do Fundao, CEP 21941-906 Rio de Janeiro, Brazil. \\ 9 KAERI, Daedeok-Daero 989-111, Yuseong-Gu, Daejeon, Republic of Korea. \\ ${ }^{10}$ Bundesamt fuer Seeschifffahrt und Hydrographie, Hamburg, Germany. \\ ${ }^{11}$ IAEA, 4a Quai Antoine 1er, MC-98000, Monaco. \\ 12 STUK, Laippatie 4, 00880 Helsinki, Finland. \\ 13 National Technical University of Athens, Iroon Polytexneiou 9, 15780 Zografou, Greece. \\ 14 NRG, Utrechtseweg 310, 6800 ES Arnhem, The Netherlands.
} F. Lamego ${ }^{8}$, V. Maderich ${ }^{3}$, B.I. Min ${ }^{9}$, H. Nies ${ }^{10}$, I. Osvath ${ }^{11}$, I. Outola ${ }^{12}$, M. Psaltaki ${ }^{13}$, K.S. Suh ${ }^{9}$

\begin{abstract}
State-of-the art dispersion models were applied to simulate ${ }^{137} \mathrm{Cs}$ dispersion from Chernobyl nuclear power plant disaster fallout in the Baltic Sea and from Fukushima Daiichi nuclear plant releases in the Pacific Ocean after the 2011 Tsunami. Models were of different nature, from box to full three-dimensional models, and included water/ sediment interactions. Agreement between models was very good in the Baltic. In the case of Fukushima, results from models could be considered to be in acceptable agreement only after a model harmonization process consisting of using exactly the same forcing (water circulation and parameters) in all models.
\end{abstract}

Keywords: Baltic Sea / Chernobyl / Fukushima Daiichi / dispersion model / cesium

\section{Introduction}

Models showing different characteristics and levels of complexity, from those based on a box-type approach to those making use of the shallow-water and advection/diffusion equations were tested in two different environments: deposition and subsequent dispersion of ${ }^{137} \mathrm{Cs}$ on the Baltic Sea from the Chernobyl nuclear power plant disaster in 1986 and the dispersion of ${ }^{137} \mathrm{Cs}$ released from Fukushima Daiichi nuclear power plant in the Pacific Ocean after the earthquake and Tsunami in March 2011 (originating from both liquid releases into the ocean and from atmospheric deposition on the sea surface). The box model POSEIDON and 3D model THREETOX integrated into the decision support system JRODOS within the EU FP7 EURATOM project PREPARE were tested within this model validation study.

\section{Methods}

Models which participated in the exercises are listed in Table 1, where appropriate references for detailed descriptions are included. They range from box models to numerical models solving simultaneously the equations for water circulation together with a sediment transport model and the radionuclide dispersion model including adsorption/release of radionuclides between water and the solid phases. Also, both Eulerian and Lagrangian dispersion models were tested.

For the Baltic Sea, models were started 6 months after Chernobyl deposition and when the first comprehensive investigation on the fallout distribution in the entire Baltic Sea was carried out in October 1986. A map of ${ }^{137} \mathrm{Cs}$ in surface water over the Baltic obtained from measurements was used as initial conditions. The five year long simulations were carried out. The same information was extracted from all the models to 
Table 1. Models participating in the exercises.

\begin{tabular}{llll}
\hline Institute & Model & Scenario & Reference \\
\hline NRPA & Box model & Baltic Sea & Iosjpe et al. (2009) \\
IMMSP & POSEIDON & Baltic Sea & Lepicard et al. (2004) \\
IMMSP & THREETOX & Baltic Sea & Maderich et al. (2008) \\
IMMSP/KIOST & I/K-E, I/K-L & Fukushima & Roland et al. (2012) \\
USEV & USEV-2D & Baltic Sea & Periáñez et al. (2013) \\
KAERI & LORAS & Fukushima & Min et al. (2013) \\
NTUA & PHOENICS & Fukushima & Psaltaki et al. (2010) \\
IEN & SisBahia & Fukushima & Lamego (2013) \\
JAEA & SEA-GEARN & Fukushima & Kobayashi et al. (2007) \\
USEV & USEV-3D & Fukushima & Periáñez et al. (2012) \\
IFREMER & MARS3D & Fukushima & Bailly du Bois et al. (2014) \\
Univ. Toulouse & SYMPHONIE & Fukushima & Estournel et al. (2012) \\
\hline
\end{tabular}

allow comparisons with field data from HELCOM (Helsinki Convention on the Protection of the Marine Environment of the Baltic Sea Area) database. These data were annual ${ }^{137} \mathrm{Cs}$ concentrations in the water column and bed sediments (mean values over several Baltic Sea sub-basins) and annual inventories in the water column and bed sediments estimated from measurements.

The overall idea in the Fukushima scenario was to harmonize models, making them run with the same forcing in a step-by-step procedure, in such a way that the main agent in producing discrepancy between models can be found.

\section{Results}

The four models applied to the Baltic Sea produced very consistent results for temporal evolution of ${ }^{137} \mathrm{Cs}$ inventories in the water column and bed sediments over the Baltic, time series of radionuclide concentrations in water and sediment at some fixed points and time series of averaged ${ }^{137} \mathrm{Cs}$ concentrations in water and sediment over several sub-basins of the Baltic. These averaged concentrations were also in good agreement with those obtained from measurements in HELCOM database. The Baltic Sea presents vertical stratification, horizontal density gradients, significant freshwater supplies and a strong decreasing salinity gradient between the entrance region of the Belt Sea and the Gulf of Finland and Bothnian Sea. It is also partially covered by ice, specially in the north and during the winter. THREETOX model includes all these processes, but they are completely neglected in USEV-2D, for instance. In spite of this, there is a remarkable agreement between these models, as well as between these two models and the box models. Surprisingly, it seems that these processes are not too relevant for radionuclide transport in the Baltic Sea since similar results are obtained with models which include them and models which do not.
The situation is completely different in the case of Fukushima releases. Results from models could be considered to be in acceptable agreement only after a model harmonization process consisting of using exactly the same water circulation, same bathymetry and the same horizontal and vertical diffusivities. The same parameters for uptake/release processes are also required to have an acceptable agreement for concentrations in the bed sediment. Since the model harmonization was carried out in a sequential way, it could be concluded that a significant part of the variability between models is caused by the description of hydrodynamics.

Given the intensity and variability of currents in the Fukushima area, as well as the presence of unsteady eddies due to current convergence here (Kuroshio from the south and Oyashio from the north), small differences in hydrodynamics produce different dispersion patterns.

\section{Conclusions}

It was found that the energetics of the considered system (magnitude and variability of currents) is essential to obtain a good agreement between different dispersion models. Good agreement can be achieved between models of very different nature in environments characterized by weak currents (e.g., the Baltic Sea). However, even similar models lead to rather different results in highly dynamic systems characterized by strong and variable currents (e.g., Fukushima region). This fact highlights that developing operational models for emergency management and decision-making support (which is one of the main application of numerical modelling) in these dynamic environments should be based on the reliable operational oceanographic model calibrated for this area. The same time it is important to note that the models that were integrated into the decision support system RODOS within EC project PREPARE - THREETOX and POSEIDON, that were 
refined within the project on the basis of the experience of the UVEV and Iosjpe et al. (2009) model development, demonstrated during the described intercomparison study "the state of the art" level of the marine dispersion modelling.

Acknowledgement. This work has been carried out in the frame of IAEA MODARIA (Modelling and Data for Radiological Impact Assessments) program and was partially supported by (a) EU FP7 EURATOM project PREPARE: Project No. 323287. (b) National Research Foundation of Korea (NRF) grant funded by the Korean government (MSIP) (MSIP: No. 2012M2A8A4025912, NSSC: No. 2012M5A1A1029210). (c) V. Maderich, I. Brovchenko, R. Bezhenar and K.T. Jung have been supported by CKJORC and KIOST (PE99304).

\section{References}

Bailly du Bois P., Garreau P., Laguionie P., Korsakissok I. (2014) Comparison between modelling and measurement of marine dispersion, environmental half-time and 137-Cs inventories after the Fukushima Daiichi accident, Ocean Dyn. 64, 361-383.

Estournel C., Bosc E., Bocquet M., Ulses C., Marselaix P., Winiarek V., Osvath I., Nguyen C., Duhaut T., Lyard F., Michaud H., Auclair F. (2012) Assessment of the amount of 137-Cs released into the Pacific Ocean after the Fukushima accident and analysis of its dispersion in Japanese coastal waters, J. Geophys. Res. 117, C1014.

Iosjpe M., Karcher M., Gwynn J., Harms I., Gerdes R., Kauker F. (2009) Improvement of the dose assessment tools on the basis of dispersion of the 99-Tc in the Nordic Seas and the Arctic Ocean, Radioprotection 44 (5), 531-536.

Kobayashi T., Otosaka S., Togawa O., Hayashi K. (2007) Development of a nonconservative radionuclides dispersion model in the ocean and its application to surface cesium-137 dispersion in the Irish Sea, J. Nucl. Sci. Technol. 44 (2), 238-247.

Lamego F.F. (2013) Advanced nuclear reactors and tritium impacts: modeling the aquatic pathway, Progr. Nucl. Energy 68, 9-22.

Lepicard S., Heling R., Maderich V. (2004) POSEIDON/RODOS model for radiological assessment of marine environment after accidental releases: application to coastal areas of the Baltic, Black and North seas, J. Environ. Radioact. 72 (1-2), 153-161.

Maderich V., Heling R., Bezhenar R., Brovchenko I., Jenner H., Koshebutskyy V., Kuschan A., Terletska K. (2008) Development and application of 3D numerical model THREETOX to the prediction of cooling water transport and mixing in the inland and coastal waters, Hydrol. Process. 22, 1000-1013.

Min B.I., Periáñez R., Kim I.G., Suh K.S. (2013) Marine dispersion assessment of 137-Cs released from the Fukushima Nuclear Accident, Mar. Pollut. Bull. 72, 22-33.

Periáñez R., Suh K.-S., Min B.-I. (2012) Local scale marine modelling of Fukushima releases. Assessment of water and sediment contamination and sensitivity to water circulation description, Mar. Pollut. Bull. 64, 2333-2339.

Periáñez R., Casas-Ruíz M., Bolívar J.P. (2013) Tidal circulation, sediment and pollutant transport in Cádiz Bay (SW Spain): a modelling study, Ocean Eng. 69, 60-69.

Psaltaki M., Florou H., Trabidou G., Markatos N.C. (2010) Modelling and assessment of pollutant impact on marine environments. In: 2nd WSEAS International Conference on Computer Engineering and Applications (CEA'10), pp. 176-180. Harvard University, Cambridge, USA.

Roland A., Zhang Y.J., Wang H.V., Meng Y., Teng Y.C., Maderich V., Brovchenko I., Dutour-Sikiric M., Zanke U. (2012) A fully coupled 3D wave-current interaction model on unstructured grids, J. Geophys. Res. 117 (C00J33), 1-18.

Cite this article as: R. Periáñez, R. Bezhenar, I. Brovchenko, C. Cuffa, M. Iosjpe, K.T. Jung, T. Kobayashi, F. Lamego, V. Maderich, B.I. Min, H. Nies, I. Osvath, I. Outola, M. Psaltaki, K.S. Suh, G. de With. A comparison of radionuclide dispersion model performances for the Baltic Sea and Fukushima releases in the Pacific Ocean . Radioprotection 51(HS2), S149-S151 (2016). 